\title{
A quest for gameful practice Edu-LARP and First CREST
}

\author{
SIMON CHRISTIE
}

This article reflects on a school's
approach to gamifying the Royal
Society Te Apārangi's First CREST
Award. The article explains how
CREST was reconceived as a quest
using elements of live action role play-
ing (LARP) and gamification, and
the tools that were used to do this. It
describes how progress was measured
using a points system and the rationale
behind using points in the first place.
Finally, the article summarises the
benefits of using gameful practice in
First CREST and next developmental
steps.

\section{Stepping into the role}

Selwyn House School is a progressive, future-focused primary school that strives to offer a programme that prepares its students to be curious, empathetic, and independent. As part of this vision, Year 7 students at Selwyn House are asked to take part in the Royal Society Te Apārangi's First CREST programme during term 2 each year. First CREST is a programme that challenges students to find solutions to practical and meaningful problems through either scientific inquiry or technological design. Our students are asked to develop a solution to either a question they have always wanted answered or a problem they have always wanted solved, then they spend the entire term planning, experimenting, and prototyping to arrive at their solution.

Before 2017 we only included scientific investigations in our programme, and we found First CREST to be a robust and engaging context for this; however, because of the number of students involved, it was challenging to guide our entire year group through while maintaining high expectations of originality and rigour in their projects. We also wanted to expand their thinking and have them consider developing technology-based projects as well. We felt that the efficacy of our science programme was not matching the potential that First CREST offered.

In 2017 the Year 7 teachers attempted to gamify CREST by redesigning it as an instance of educational live action role playing (edu-LARP). This effort was continued and honed in 2018. At the time we had set ourselves professional goals of learning about, and applying, gamification strategies around our teaching. It became clear that the CREST Award was a rich context in which to do this because we saw that progress could be chopped into discrete, predictable phases, which implied that students could pilot themselves through the programme if they had an appropriate framework. We set about creating this framework as a game.

We had no experience of gamification or knew of any gamification platforms; however, a misspent youth playing computer-based strategy and role-playing games (RPGs) had given me some experience of what they could look like, and we had all used Kahoot before (https:// kahoot.com/). The common elements in these games gave us starting points to build our own game from and provided a ready-made tool kit of language and concepts to draw upon. These elements included:

- a points system

- meaningful decision making

- a compelling narrative

- goal centredness.

In addition, we had three main requirements for our game. It had to be:

- cheap

- fun

- independently navigable by the students and promote self-regulation.

We found several gamification sites on the internet and most of them would meet at least two of our three criteria, but none would meet them all. Some sites had free versions, but without expensive upgrades they often had untenable restrictions, such as only allowing a single teacher login. All sites appeared to be fun to use, but they could also be 
unnecessarily elaborate for what we wanted. CREST had to be the purpose of our game, not the other way around.

Eventually, we realised that we could create our own website for free using Google Sites and customise it specifically to what we wanted CREST to be like.

This we did, and we called it CREST World.

\section{The inside workings}

Students were invited to go on a quest. Progress through the quest was measured by earning eXperience Points (XP); earning 12,000 XP by the end of the term would allow a student to receive a much-prized CREST badge from the Royal Society Te Apārangi. The required points were divided up into 6 levels of 2,000 XP each, with each level correlating to a separate phase in our CREST process and a separate chapter in an accompanying narrative. XP were tallied on a Google Sheet as they were earned.

Within each level students could earn XP by completing prescribed tasks of varying difficulty; for example, sending an email to an expert would earn only a few XP, whereas contacting them by phone, which is harder, would earn many more. The goal was to create a dynamic, pick-a-path learning journey where one student's choices could be different from another's yet still end at the same result. Independence and self-regulation were emphasised, and the students were led to taking constructive risks to gain greater rewards.

We did not gamify the processes of scientific inquiry or engineering design themselves so as not to obfuscate what they are or how they work. Only the framework that guided the students through the award was gamified.

Contemporary research has shown that the LARP approach can have a positive effect on learning (Schwartz, 2017) and my youthful experience with RPGs gave me an idea of what an accompanying narrative could look like. Through a series of transcripts, memos and other communications a space-themed story unfolded across the phases of the game.

\section{The Earth Dies}

The students were given access to the CREST World website, but initially only one page was navigable. The initial chapter, called "The Earth Dies", included a "U.N. Advisory Notice", printed in Courier New to replicate the style of old computer printouts, which warned of the imminent ecological collapse of the planet. The students were advised to rush to shuttles that were leaving with refugees for a new home, far, far away. The notice warned that "it is imperative that we improve our futures by not repeating the mistakes of our pasts." They were expected to choose either a science or engineering specialty, then spend their time on the long journey researching and developing products to make life better at their new home.

From there on, the students would have new pages unlocked for them at preplanned times that suited the milestones in our programme. Timing was vital, as

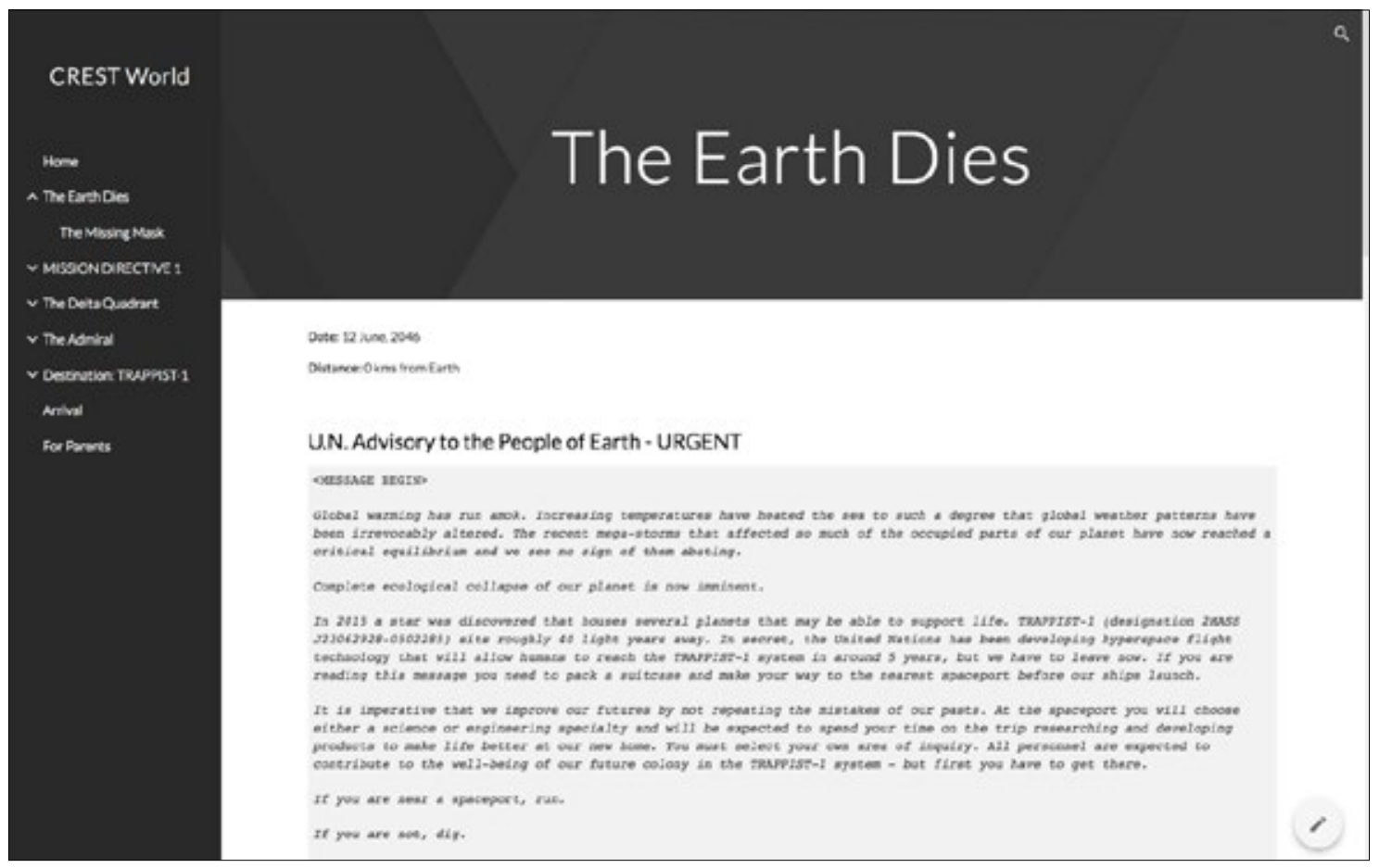




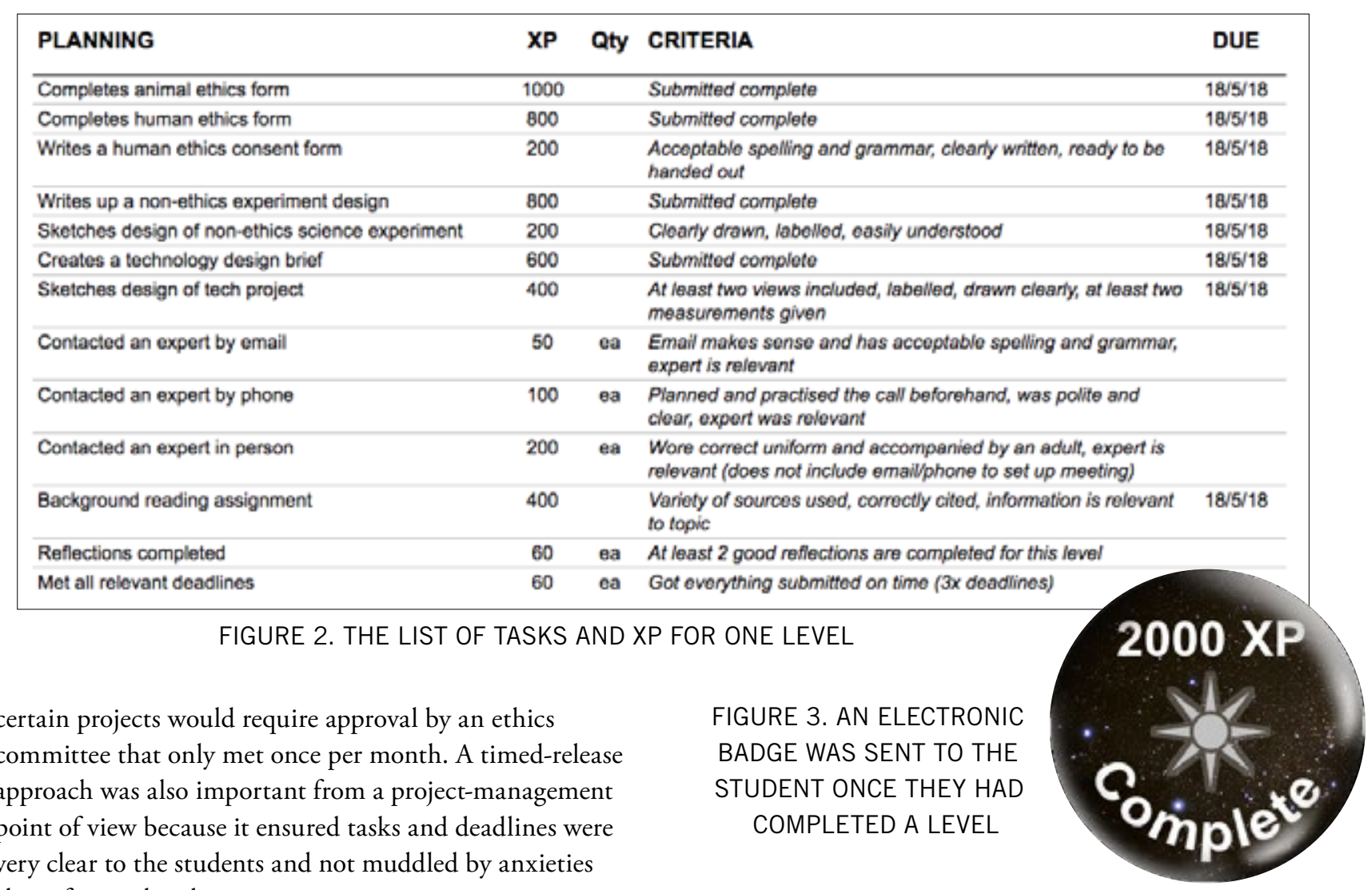
about future details.

Each phase in the narrative included humour, a subtle pop-culture reference that the students would be unlikely to get, and a task that needed to be completed by volunteers who wanted- or needed-extra XP. The task was never shown until enough students had blindly volunteered for it, in order to increase the tension and risk. These tasks included making the hapless students run around at morning tea wearing art shirts as trousers, a space-themed quiz, and making a paper dart that had to fly further than the teachers' (which was disappointingly easy to do).

\section{Points of difference}

When deciding on an appropriate points system we felt challenged by our, admittedly, simplistic understanding that rewards are "bad" and intrinsic motivations are "good". A contemporaneous episode from the Freakonomics podcast (Lambert, 2017) added to our internal conflict; it noted that psychologists could provide an abundance of evidence to show why incentivising learning was counterproductive, whereas behavioural economists could robustly argue the exact opposite view. If even the academics could not agree on whether reward points were good or bad, what chance did we have?

We decided to use XP because it is a common currency in computer and pen-and-paper RPGs. We did not wish to reward the students as such, but

\section{TABLE 1. A SUMMARY OF THE CREST WORLD NARRATIVE}

\begin{tabular}{|c|c|c|}
\hline Level & Summary of the CREST World Page & Purpose of the Level \\
\hline 0 & $\begin{array}{l}\text { A U.N. Advisory warning of } \\
\text { impending doom if anyone stays } \\
\text { on the planet Earth. }\end{array}$ & $\begin{array}{l}\text { To introduce the quest } \\
\text { and brainstorm a list of } \\
\text { potential topics for study }\end{array}$ \\
\hline 1 & $\begin{array}{l}\text { A mission briefing demanding a } \\
\text { project proposal, posted from a } \\
\text { refugee camp inside Moonbase } \\
\text { Alpha. }\end{array}$ & $\begin{array}{l}\text { To assess the best topic } \\
\text { ideas and select one to } \\
\text { take further (prerequisite } \\
\text { of } 2,000 \text { XP earned) }\end{array}$ \\
\hline 2 & $\begin{array}{l}\text { An email from the housing } \\
\text { supervisor in the Delta Quadrant } \\
\text { requesting a written plan of their } \\
\text { project, in order to correctly assign } \\
\text { them to an appropriate U.N. } \\
\text { Research station. }\end{array}$ & $\begin{array}{l}\text { Writing a project plan } \\
\text { for the selected topic for } \\
\text { the teachers to approve } \\
\text { (prerequisite of } 4,000 \mathrm{XP} \\
\text { earned, etc.) }\end{array}$ \\
\hline 3 & $\begin{array}{l}\text { A transcript of the welcome } \\
\text { speech by an irascible and } \\
\text { terrifying military officer, } \\
\text { threatening dire consequences to } \\
\text { the beloved soft toys of anyone } \\
\text { who brings his research station } \\
\text { into disrepute when working on } \\
\text { their project. }\end{array}$ & $\begin{array}{l}\text { Completing experiments } \\
\text { or prototyping design } \\
\text { solutions }\end{array}$ \\
\hline 4 & $\begin{array}{l}\text { The transcript of an } \\
\text { announcement by Miss Julie } \\
\text { McCoy, the spaceship's recreation } \\
\text { officer, who advertises an arts } \\
\text { and crafts evening in the ship's } \\
\text { recreation room. }\end{array}$ & $\begin{array}{l}\text { Creating an effective } \\
\text { display of their learning }\end{array}$ \\
\hline 5 & $\begin{array}{l}\text { A formal invite from the governor } \\
\text { of the new colony to attend the } \\
\text { final project presentations. }\end{array}$ & $\begin{array}{l}\text { Explaining the inquiry to } \\
\text { a visiting academic, who } \\
\text { judges the projects }\end{array}$ \\
\hline
\end{tabular}


rather acknowledge that they had progressed in their knowledge; therefore, on a philosophical level, the use of $\mathrm{XP}$ was useful because it strongly correlated with what we actually wanted to measure-experience. The predefined values of XP were granted when work was completed to a minimum standard; they did not vary to indicate the work's quality. We deliberately chose to level up at 2,000 $\mathrm{XP}$ rather than $100 \mathrm{XP}$ so the students did not equate $100 \mathrm{XP}$ with $100 \%$, which implies a qualitative statement about the work submitted.

In our philosophy, the students were not rewarded per se; they were simply given a graphic indicator of where they were in the process, much like fundraising thermometers for community projects.

\section{Gaining experience}

Differences can be drawn between LARP and gamification (Balzer \& Kurz, 2015), but our programme attempted to loosely combine elements of both into a more general practice of gameful learning. Although no formal research or data gathering was undertaken to measure the success of this project, anecdotally it was clear that CREST World and the gamification of First CREST was a highly successful enterprise. Teachers, students, and parents all saw benefits to the students' knowledge, self-organisation, and risk taking. One parent told us her daughter remained motivated throughout CREST because the XP schedule supported her through the process, so that nothing was too big to accomplish. We have also found that the number of technology projects the students undertake has increased markedly, and in 2017 three of our ten entries into the Canterbury-Westland Science and Technology Fair won prizes. In 2018 that number rose to seven. We certainly feel that we are achieving our goals of increasing originality and rigour in our science programme.

However, several elements still remain to be improved to make CREST World more accessible and fun.

Balancing the XP awarded to tasks so that the students get fair pay for fair work is challenging. Unbalanced XP allocations made certain paths more desirable than others, increasing the linearity of the quest. The addition of sidequests and chance, perhaps through more randomised events as part of the narrative, may create opportunities and motivation to choose a road less travelled.

As an edu-LARP, CREST World was heavy on live action but light on role play. Future revisions could include more performance elements, giving students roles they can better engage with, as well as non-playing characters, cosplay, or dead ends in the story. We could add the ability for students to customise their characters with non-contributing upgrades, such as clothes, pets, or habitats, to maximise engagement.
Finally, because CREST is completed every year, it would be helpful to have at least two narratives prepared so the process is not too repetitive for teachers and alternate year groups can have different experiences.

\section{Practising gameful practice}

Like a good game, designing a gamification platform has proven to be easy to start but difficult to master. Although we consider CREST World's design a success, we do not consider it complete; however, we have run the CREST Award as a game for 2 years now and over that time we have noted increased levels of engagement, selfregulation and constructive risk-taking in our students. The narrative-based gamification process provided a useful framework through which the students could guide their own learning and was very useful as a projectmanagement tool for the teachers.

\section{Acknowledgements}

I would like to acknowledge Fiona McKenzie and Laura Wells, my CREST World co-creators, and thank Fiona in particular for proofreading this manuscript. I would also like to thank Dr Lyn Bird for her support of our vision for gamification and her helpful suggestions when editing this paper.

\section{References}

Schwartz, N. (2017, February 10). Learning at play: Integrating live action role-playing into the classroom [Blog post]. Retrieved from https://carleton.ca/tasupport/2017/bloglearning-play-integrating-live-action-role-playing-classroom/

Lambert, E. (Producer). (2017, April 5). Could solving this one problem solve all the others? [Audio podcast]. Retrieved from http://freakonomics.com/podcast/solving-one-problemsolve-others/

Balzer, M. \& Kurz, J. (2015). Learning by playing—Larp as a teaching method. Retrieved from https://nordiclarp. org/2015/03/04/learning-by-playing-larp-as-a-teachingmethod/

Simon Christie teaches Year 7 at Selwyn House School, Christchurch. He has a passion for project-based learning, particularly through making and engineering design. In 2017 he won Education HQ's Unsung Hero-Technology award for his work in codeveloping a new mechatronics curriculum for the school.

Email: s.christie@selhouse.school.nz 